\title{
Dimensão ergo-dialógica do trabalho do tradutor intérprete de Libras/Português: dramáticas do uso de si e debate de normas no ato interpretativo
}

Ergo-Dialogical Dimension of the Brazilian Sign Language/Portuguese Interpreter's Work: Use of Self Dramatics and Discussion of Norms in the Interpretative Act

Vinícius Nascimento*1

Pontifícia Universidade Católica de São Paulo

São Paulo / Brasil

RESUMO: Este artigo tem por objetivo conduzir uma discussão sobre a atividade de trabalho do tradutor intérprete de libras/português (TILS) de uma perspectiva ergo-dialógica. A partir das concepçôes da Ergologia, abordagem filosófica que visa compreender o trabalho para transformá-lo e da perspectiva dialógica de estudos da língua e da linguagem, realiza-se a análise de uma narrativa produzida por um TILSP sobre uma situação de interpretação na esfera universitária. Compreende-se, aqui, a atividade de interpretação em "linguagem como trabalho" e, por meio disso, analisa-se as interfaces, dramáticas, intercorrências e escolhas enunciativo-discursivas manifestas no posicionamento responsável do intérprete enquanto enunciador/mediador das relaçōes entre surdos e ouvintes.

PALAVRAS-CHAVE: Intérprete, Libras, Abordagem Ergológica, Perspectiva Dialógica.

\footnotetext{
*nascimento_v@outlook.com

${ }^{1}$ Mestre e Doutorando em Linguística Aplicada e Estudos da Linguagem (LAEL/PUC$\mathrm{SP}$ ). Bolsista CNPq. Coordenador e professor do curso de Tradução e Interpretação de Libras/Português do Instituto Superior de Educação de São Paulo/Singularidades.
} 
ABSTRACT: This paper aims to conduct a discussion on the work activity of the Brazilian Sign Language/Portuguese interpreter and translator from an ergo-dialogical perspective. An analysis of a narrative produced by a Brazilian Sign Language translator/interpreter was carried out regarding an interpretation act within the ambit of a university based on the concepts of (i) Ergology, a philosophical approach that attempts to understand work in order to transform it and (ii) the dialogical perspective of language studies. The interpretation activity is here understood as "language as work", through which the interfaces, dramatics, problems, and enunciative-discursive choices manifested in the interpreter's responsible positioning as an enunciator/mediator of relations between deaf and hearing people are analyzed.

KEYWORDS: Interpreter, Brazilian Sign Language, Ergologic Approach, Dialogic Perspective.

\section{INTRODUÇÃO}

Somos todos, como seres humanos, atormentados por debates internos, "debates de normas" mais ou menos visíveis aos outros e a nós mesmos, mais ou menos invisiveis também.

Yves Schwartz

Eu, que realmente penso e sou responsável pelo ato [akt] $d o$ meu pensar, não tenho lugar no juizo teoricamente válido. $\mathrm{O}$ juízo teoricamente válido é, em todos os seus momentos, impenetrável para a minha atividade [akyivnost'] individualmente responsável.

Mikhail Bakhtin

A atuação do Tradutor Intérprete de Libras/Português (TILSP) ${ }^{2}$ em esferas de atividade profissional vem se intensificando nos últimos vinte anos. Essa atividade iniciou-se com proporção significativa, conforme nos

\footnotetext{
${ }^{2}$ Essa designação - Tradutor Intérprete de Libras/Português - é realizada pelo Decreto 5.626/05 que regulamenta a Lei de Libras, 10.436/02. A atividade de trabalho desse profissional concentra-se, na maioria das vezes, na interpretação da Libras para o português oral e vice-versa. No entanto, algumas vezes o TILSP se depara, em sua atuação, com textos escritos na língua portuguesa, seja pela esfera em que ele é convocado a atuar, como a midiática (NASCIMENTO, 2011), por exemplo, ou porque existe a necessidade de tradução da produção escrita em português dos surdos para a Libras e vice-versa (RUSSO, 2009).
} 
mostra alguns pesquisadores, no seio das esferas religiosas (ROSA, 2005; QUADROS, 2007; LACERDA, 2009; SILVA, 2010). Nesse contexto, a interpretação da língua de sinais não era considerada uma atividade profissional per se, com remuneração, carga horária, direitos e deveres, mas era abordada - e ainda é quando falamos da atuação no universo eclesiástico - do ponto de vista do voluntariado, isto é, quando pessoas interessadas em aprender a língua de sinais recebiam instruções de como realizar performances interpretativas nas cerimônias das instituições, sobretudo, cristãs de matriz protestante (SILVA, 2010).

A expansão dessa atividade para além do universo religioso aconteceu na medida em que os movimentos sociais de e para surdos iniciaram a protagonização de lutas em prol do reconhecimento de sua língua, comunidade, identidade e cultura, que culminaram em uma legislação que reconhece os direitos linguísticos dessa comunidade (NASCIMENTO, 2012).

A Lei de Libras 10.436/02 (BRASIL, 2002) e o Decreto que a regulamenta, 5.626/05 (BRASIL, 2005), foram determinantes para a ampliação da presença do surdo nos diferentes espaços e, com isso, para a configuração de uma identidade profissional do TILSP. Com essas conquistas e deslocamentos, a inserção dos TILSP em outros espaços para além do religioso foi, também, se expandindo e como resultado surgiu, então, a necessidade de formação que contemple a atuação desse profissional em diferentes esferas de atividade.

A inclusão dos surdos na sociedade e a necessidade de práticas de mediação discursiva entre falantes e não falantes da língua de sinais instaurou um movimento sócio-histórico de extrema relevância para esse profissional, uma vez que sua prática considerada, até então, voluntária, missionária e assistencialista, passa a ser abordada de outra perspectiva: a do trabalho, envolvendo, com isso, direitos, deveres, normas e prescrições.

Desse modo, a atuação do TILSP fora do contexto religioso surge da presença maciça de surdos nos diferentes espaços, como efeito cascata da legislação que reconhece os seus direitos como minoria linguística. ${ }^{3}$

\footnotetext{
${ }^{3}$ A comunidade surda vem sendo abordada como minoria linguística por pesquisadores que encaram a surdez de uma perspectiva sócio-antropológica, isto é, quando a surdez é descrita não como patologia, deficiência ou, ainda, como experiência de falta, mas como traço constitutivo da identidade. Essa perspectiva considera que, por ser a surdez um traço identitário à língua de sinais, a visualidade e a cultura surda
} 
Essa ampla e significativa inserção desloca esse profissional que atuava sem formação em nível superior e sem grandes prescrições para orientar sua atividade, no contexto religioso e, também, familiar, ${ }^{4}$ para esferas em que as coerçōes discursivas, prescritivas e formativas são latentes e que ele, como profissional "convocado" a estar nesses novos espaços, desconhece.

$\mathrm{O}$ drama $^{5}$ de como lidar com as questôes presentes em novas esferas de atuação torna-se gritante quando, durante a atividade, lhe são exigidos conhecimentos e competências que ele não possui e que são determinantes para o estabelecimento dos sentidos discursivos durante a interação mediada entre os seus dois interlocutores diretos.

Temos, portanto, uma série de problemáticas envolvidas nessa atuação: o deslocamento para esferas de atividade que são desconhecidas; a exigência de competências que ele, do ponto de vista teórico e formativo, não possui; a ausência de uma formação que lhe ofereça, no mínimo, antecipações de como ele deverá agir em certas situações; e, acima de tudo, prescrições que possam orientar o seu fazer.

Essas problemáticas foram significativas para nosso deslocamento do lugar de trabalhador, enquanto TILSP que vivenciou a atividade de interpretação em contextos profissionais diversos (educacionais, midiáticos, artísticos, coorporativos, etc.), para observar esse fazer de outro ponto de vista: o da pesquisa.

$\mathrm{O}$ vazio de normas presente no universo da tradução/interpretação da língua de sinais constitui-se em um balizador para a vivência de situações dramáticas, conflituosas e, muitas vezes, constrangedoras, uma vez que,

constituem-se como alguns dos elementos que definem essa comunidade como minoria linguística (SKLIAR, 2005; QUADROS, 1997; MOURA, 2000; STROBEL, 2008). Neste artigo, assumimos a concepção sócio-antropológica como base fundadora das discussōes que serão aqui realizadas, uma vez que a figura do TILSP convoca, por si só, o reconhecimento da língua de sinais como língua e do surdo como sujeito que possui diferenças identitárias e não marcas de deficiência.

${ }^{4}$ Não se sabe o momento exato em que a interpretação da língua de sinais iniciou, mas alguns autores vêm hipotetizando que as primeiras cenas de interpretação dessa língua aconteceram dentro das famílias de surdos em que os filhos ouvintes, por terem acesso às duas línguas, realizavam a mediação na comunicação de seus pais com pessoas ouvintes e fontes de discursos orais, tal como, por exemplo, a televisão (RUSSO, 2009; PEREIRA, 2010).

${ }^{5}$ Drama/dramática são conceitos advindos da perspectiva ergológica e serão melhor explorados adiante. 
quando não há normas para orientar a atividade ela pode ficar obscura, obtusa e sem direção. A legislação existente, que arbitra como norma antecedente e prescritiva, não aborda o fazer interpretativo, o que torna ainda mais complexa uma atuação sem formação e antecipações. Desse ponto de vista, "a existência, em todos os níveis, de normas gerais que não consideram as singularidades históricas e individual é uma aquisição 'não negociável' de nossa humanidade" (SCHWARTZ, 2011, p.135).

Essa é a discussão que temos realizado em nossa pesquisa de doutorado em andamento. ${ }^{6}$ A base teórica que fundamenta nosso estudo é composta pelo diálogo entre duas perspectivas teórico-metodológicas: (i) pela perspectiva enunciativo-discursiva de estudos da língua e da linguagem, que pode ser enxergada, lida, extraída, compreendida nas obras escritas pelos membros do Círculo de Bakhtin; e (ii) pela Ergologia, abordagem filosófica de pensar, encarar e transformar o trabalho, surgida na França em meados da década de 1970, por meio de um diálogo entre o filósofo Yves Schwartz com outros estudiosos da atividade humana. A discussão proposta nesta pesquisa, sobre a atuação do TILSP, tem se direcionado para o diálogo de saberes que se estabelece durante o ato interpretativo de profissionais em processo de formação profissional, no contexto da pós-graduação lato sensu.

Neste artigo, apresentamos uma análise, com base nessas duas perspectivas, sobre as dramáticas da atividade vivenciadas pelo TILSP e que estão diretamente ligadas à prática de interpretação da língua de sinais em situações de trabalho. No entanto, a análise que será realizada aqui não foi retirada do corpus de nossa pesquisa por ele estar ainda em processo de coleta, mas foi colhido em um curso de formação para TILSP, em uma instituição de educação superior de ensino particular da cidade de São Paulo, o mesmo contexto de coleta de dados para a nossa pesquisa.

Trata-se de uma narrativa escrita, realizada por um TILSP em relação à sua atuação durante uma situação de interpretação na esfera universitária. A orientação dada foi para que os intérpretes descrevessem situações que eles mesmos considerassem dramáticas sobre seu trabalho. Dentre um total de

\footnotetext{
${ }^{6}$ A pesquisa de doutoramento intitulada Tradutor intérprete de Libras/Português: formação profissional em perspectiva ergo-dialógica está sendo realizada no Programa de Pós-graduação em Linguística Aplicada e Estudos da Linguagem da PUC-SP, sob a orientação da Profa. Dra. Beth Brait, com fomento do Conselho Nacional de Desenvolvimento Científico e Tecnológico (CNPq) para ser realizada no período de fevereiro 2013 a fevereiro 2017 (Processo 164738/2013-4).
} 
vinte e quatro, escolhemos uma em que, a nosso ver, transparecem categorias que podem ser lidas do ponto de vista do discurso, enquanto ato responsável, conforme nos demonstra a perspectiva bakhtiniana, bem como do ponto de vista das situações reais de trabalho, tal como é proposto pela Ergologia.

Esta análise preliminar presta-se a estabelecer um diálogo entre as duas perspectivas anunciadas, que fundamentam o nosso arcabouço teóricometodológico e colaboram com a discussão atual sobre o trabalho do TILSP e as diferentes designações que a ele são dadas pelas normas legislativas.

Perseguiremos a dimensão ergológica dessa atuação que pode revelar a relação com a existência e/ou vazio de normas para orientar o seu fazer; e a dimensão dialógica do ato de linguagem envolvendo a interpretação que, na busca pela transposição dos sentidos do discurso-fonte, pode apresentar relaçóes de assimetria entre o triângulo interacional presente no ato (locutor/ interlocutor ouvinte, intérprete e locutor/interlocutor surdo).

Para tanto, primeiramente, introduziremos o leitor na perspectiva ergológica e nas suas devidas intersecções com a Linguística Aplicada (LA), pontuando o quanto esse diálogo epistemológico tem sido importante para a compreensão das atividades humanas, em especial a de trabalho, por meio da materialização da linguagem. Na sequência, realizaremos uma explanação do ato interpretativo pelo viés do dialogismo bakhtiniano para, então, conduzirmos a discussão sobre a relação linguagem/trabalho para compreender e defender a atividade do TILSP, do ponto de vista da "linguagem como trabalho", na análise da narrativa coletada.

\section{ERGOLOGIA E LINGUÍSTICA APLICADA: intersecção teóri- co-metodológica para o estudo da linguagem e das atividades humanas}

A Ergologia é uma abordagem pluridisciplinar que nasceu na França, em meados da década de 1970, com o objetivo de observar, encarar e transformar a atividade humana, especialmente a atividade de trabalho. Com um olhar para as ações que permeiam o fazer dos trabalhadores, a Ergologia nasce com a proposta de observar e, com isso, intervir com os sujeitos envolvidos nesse fazer, com as histórias que ali são inscritas e os saberes que são produzidos por eles durante a atividade, com o objetivo de transformar 
e, possivelmente, melhorar as atividades humanas industriosas. ${ }^{7}$

Essa perspectiva/postura/abordagem, que ajuda a compreender que trabalhar também é pensar (ATHAYDE \& BRITO, 2007), surge com as publicaçōes elaboradas pelo filósofo Yves Schwartz, na Université de Provence, em diálogos com outros intervencionistas do trabalho como o linguista bakhtiniano Daniel Faita, o ergonomista Jacques Duraffourg, o sociólogo Pierre Tranquet e o Psicólogo do Trabalho Yves Clot.

A Ergologia não é uma disciplina, tal como é a Sociologia, a Psicologia, a Linguística e outras: ela caracteriza-se por uma abordagem pluridisciplinar. Segundo Schwartz (2013), o trabalho enquanto atividade humana se fundamenta em dimensões ergonômicas, psicológicas, linguísticas, jurídicas, sociológicas, etc. Por essa razão, não se pode apoiar em um campo particular, pois clama por um olhar interdisciplinar que busque abarcar o constante processo de renormalização das normas antecedentes (o prescrito), a partir dos saberes que são realizados na própria atividade (o realizado).

$\mathrm{Na}$ apresentação à edição brasileira da obra Trabalho e Ergologia. Conversas sobre a atividade humana que publica diálogos entre Schwartz e outros pesquisadores que se inscrevem nessa abordagem, Athayde e Brito (2007, p.5) afirmam que se pode falar, então, em "ergonomistas-ergólogos, em profissionais de gestão-ergólogos, economistas-ergólogos, linguistasergólogos, trabalhadores-ergólogos [...]" e, no nosso caso, podemos, ousadamente, falar de tradutores/intérpretes-ergólogos.

Esta é uma abordagem que encara a atividade como uma arena de debates entre normas heterodeterminadas, que antecedem seu andamento, e as experiências recriadoras dos sujeitos, chamadas de renormalizaçôes, que se processam em cada gesto, situação e práticas linguageiras (FRANÇA, 2004). O trabalhador, então, é a figura centro da Ergologia, visto que tudo, nessa perspectiva, deve ser pensado a partir das relaçóes que ele estabelece entre si consigo mesmo, com os outros e com a atividade.

\footnotetext{
${ }^{7}$ Atividade industriosa corresponde a toda e qualquer atividade de trabalho realizada pelo homem, seja ela economicamente reconhecida (um trabalho assalariado) ou não: trabalho para si, trabalho doméstico, atividade esportiva e lúdica, etc. Para Schwartz (2004), toda atividade humana é comensurável a uma experiência, a “[...] uma negociação problemática entre normas antecedentes e as normas de sujeitos singulares, sempre a serem redefinidas aqui e agora" (p.39) e isso independe de onde, quando e quem realiza a atividade, pois toda ação humana envolve usos de si para si e para os outros.
} 
O prefixo ergo vem de uma palavra grega que significa 'ação, trabalho, obra'. Aponta para a energia, a vitalidade daquele que trabalha, a ênfase não está no trabalho visto por uma pessoa exterior. Aí está o ângulo sob o qual abordamos o trabalho: colocamo-nos tanto quanto possível do ponto de vista daquele que trabalha. Nós nos centramos sobre a relação que a pessoa estabelece com o meio no qual ela está engajada (SCHWARTZ; DURRIVE, 2007, p.297, grifo do autor).

O trabalho, portanto, na perspectiva ergológica, deve ser compreendido a partir de três polos distintos, mas que se influenciam e se completam por meio de "uma dialética, um compromisso, um encontro [...], parâmetros indissociáveis e presentes em toda a situação de trabalho" (SOUZA-E-SILVA, 2008, p.4).

Por meio da metáfora do triângulo, Schwartz (2011) aborda a atividade de trabalho considerando as seguintes pontas:

(i) Saberes acadêmicos/constituídos, que são os conhecimentos formalizados por meio de disciplinas. Tudo aquilo que é ensinado e organizado em diferentes suportes como livros, leis, documentos, manuais, organogramas. Esse conjunto de formalizações é denominado de normas antecedentes e correspondem às normas fora da atividade. Não são prescriçōes para o fazer stricto sensu, mas envolvem princípios "não negociáveis" (SCHWARTZ, 2011) desse fazer.

(ii) Saberes investidos, que corresponde àquilo que é construído pelo trabalhador durante a sua atividade. Nesse polo, a dimensão empírica é que é constitutiva, visto que todo sujeito, ao trabalhar, carrega consigo histórias, valores, princípios que são redimensionados durante o fazer. Esse polo corresponde ao chamado patrimônio de conhecimento advindos do próprio trabalhador.

(iii) Debate de valores e o uso de si, que envolve, para o trabalhador, para o pesquisador ou para qualquer sujeito envolvido em uma atividade humana, um conflito de ajuste entre os saberes que são instituídos previamente, as normas antecedentes e os saberes investidos durante a própria atividade de trabalho que, pelas especificidades do próprio fazer, obrigam o trabalhador a renormalizá-las. Esse polo "é o lugar da 
renormalização, das reavaliações, do retratamento de normas e de valores que estão enraizados nas gestôes da atividade" (SOUZA-E-SILVA, 2008, p. 4)

Nesse prisma, o enfoque ergológico considera a existência de uma sinergia entre os saberes acadêmicos, os saberes da ação/experiência e o debate de valores que atravessa a atividade. Passa-se, então, a compreender o trabalho como um debate sempre renovado entre normas antecedentes e suas tentativas de renormalização, historicamente contextualizadas e balizadas pelo nível local de atuação concreta do trabalhador (SOUZA-E-SILVA, 2008).

No Brasil, a Ergologia é introduzida mais fortemente por meio de um diálogo com os estudos da linguagem na década de 1990 e tem ganhado espaço significativo no âmbito da Linguística Aplicada. Os estudos iniciais sobre o binômio linguagem/trabalho iniciaram com a parceria interinstitucional entre pesquisadores brasileiros e franceses para o estudo das atividades de trabalho pela linguagem (SOUZA-E-SILVA, 2008; SOUZAE-SILVA \& FAITA, 2002).

Na LA como (in) disciplina, conforme provoca Moita Lopes (2006), a Ergologia, como abordagem, tem sido relida e submetida às coerções que esse próprio campo se propõe a ser, isto é, em vez de aplicação da linguística stricto em determinados campos, em especial o de ensino, os princípios ergológicos são abarcados para observação e enfrentamento de "práticas linguísticas" (MOITA LOPES, 2006) no/pelo trabalho. Nessas práticas pode-se observar como se manifesta, se configura e se estabelece o trabalho em suas diferentes dimensões e possibilidades, já que o "estudo das práticas linguageiras constitui a via que dá acesso ao conhecimento de um plano secundário no qual se situa o verdadeiro objeto" (FAITA, 2002, p.46). No caso da Ergologia em diálogo com a LA, o objeto que se instaura é denominado de práticas linguageiras em situaçôes da atividade de trabalho (FAITA, 2002; NOROUDINE, 2002).

Dentre as grandes contribuições da Ergologia para as Ciências Humanas e, em especial para as Ciências da Linguagem, está a de observar, por meio do discurso, como os dramas, os saberes, as histórias aparecem e são narradas pelos sujeitos que a protagonizam. Para o pesquisador, no contexto da LA, que elege as situações de trabalho como locus para pesquisa, é necessária uma nova postura em "[...] que é obrigado a recorrer a noções e/ 
ou categorias de análise advindas de outras disciplinas e a fazer empréstimos diversificados no âmbito de sua própria disciplina [...]" (SOUZA-E-SILVA, 2002, p.63).

A natureza transgressora, mestiça e ideológica da LA (MOITA LOPES, 2006) autoriza os que nela se inscrevem a olhar as práticas de linguagem em situações reais, promovendo intensos diálogos entre diferentes saberes em contextos diversos, dentre os quais, os que possuem o ato de trabalho como centro. No contraponto, a condição pluridisciplinar da Ergologia possibilita, desse modo, convocar diversos conhecimentos que contribuem de maneira significativa para encarar o trabalho humano a partir da linguagem, e esses conhecimentos podem ser invocados tendo como ponto de partida os dados de realidade que o pesquisador encontra no fazer presente, no contexto observado.

Tanto a análise que apresentaremos nesse artigo quanto a nossa pesquisa de doutoramento se inscrevem na LA enquanto campo que permite e autoriza promover diálogo com diferentes bases epistemológicas. A Ergologia, na sua condição pluridisciplinar, é a abordagem com que dialogamos por enxergarmos nela instrumentalidades conceituais (e didáticas!) para o enfrentamento, descrição e intervenção no trabalho do TILSP.

\section{ENQUADRAMENTO DA ATIVIDADE DO TILSP: abordagem ergológica}

Abdallah Nouroudine (2002) explora a tripartição proposta por Jhonson e Caplan, em 1979, sobre a relação trabalho/linguagem: a "linguagem como trabalho", a "linguagem no trabalho" e a "linguagem sobre o trabalho".

A primeira relação apresenta complexidade significativa, uma vez que a linguagem é, ela própria, a atividade de trabalho. Não apenas a compõe, mas, ao contrário, a constitui e a fundamenta, tornando aquilo que é complexo, tanto do ponto de vista da atividade quanto da linguagem em si, um todo, quase que indissolúvel e impossível de divisão para qualquer tipo de análise. Nesse prisma, o autor afirma que "a 'linguagem como trabalho' não é somente uma dimensão, dentre outras, do trabalho, mas ela própria se reveste de uma série de dimensões" (NOROUDINE, 2002, p. 21).

Para Nouroudine (2002), a "linguagem como trabalho" é econômica visto que a comunicação nessas situações é utilizada, por exemplo, para 
algumas atividades específicas, como a do fazer do professor em que o falar constitui a atividade e a gestão do próprio tempo dessa atividade. Sem a linguagem a função do professor é apagada. Podemos notar esse fato quando um docente adquire uma disfonia, ${ }^{8}$ seja ela de qual ordem for (orgânica ou psíquica), e é afastado ou realocado das atividades pedagógicas. A linguagem é social, na acepção bakhtiniana do termo, visto que é entre sujeitos que a enunciação se constitui, é na interação de duas pessoas organizadas socialmente que ela nasce e perdura, ecoando para frente e para trás, por serem, sempre, enunciados novos, porque são falados por novos sujeitos, mas são, também, antigos, porque o sujeito que diz não é o primeiro a dizer (BAKHTIN/VOLOCHÍNOV, 2009). E a linguagem é ética porque todo enunciado envolve, per se, um dado compromisso axiológico na sua conjuntura social, "sem uma determinada visão ou modelo de humanidade no qual as contradições sociais não se apresentam necessariamente como 'competição' por se constituírem um fator de progresso, pode, antes, abrir o campo de debates" (NOROUDINE, 2002, p.21).

Nessa primeira relação, no exame das situações de trabalho, nas palavras de Nouroudine (2002), não se analisa, apenas, o discurso pré e/ ou pós-experiência, mas, sobretudo em todas as partes da atividade, as dimensões fisiológicas, cognitivas, subjetivas, sociais, etc. que se cruzam na complexidade de fazer do trabalhador pela linguagem.

A segunda divisão, "linguagem no trabalho", corresponde a uma não participação da linguagem na atividade em si o que não significa que, ao contrário da primeira divisão, a linguagem não seja plenamente atividade. "Enquanto a 'linguagem como trabalho' é expressa pelo ator e/ou coletivo dentro da atividade, em tempo e lugar reais, a 'linguagem no trabalho' seria, antes uma das realidades constitutivas da situação de trabalho global na qual desenrola a atividade" (NOROUDINE, 2002, p.22). O grande ponto aqui é que a linguagem no trabalho pode veicular conteúdo, muitas vezes de natureza variada ao que a atividade realmente é, como, por exemplo, conversas sobre questóes pessoais durante o fazer industrioso.

E a terceira e última relação, "linguagem sobre o trabalho", liga-se à produção de saber sobre o fazer dos trabalhadores. Essa questão, longe de ser apenas um recurso utilizado por pesquisadores para compreender o trabalho por meio do discurso dos sujeitos, é um aspecto de grande demanda entre

\footnotetext{
${ }^{8}$ Alteração no funcionamento da voz.
} 
os próprios protagonistas das diferentes atividades laboriosas. No entanto, dificilmente os trabalhadores encontram espaços para falar sobre seu próprio fazer dentro do ambiente de trabalho. Essa "linguagem sobre o trabalho" é manifesta em espaços fora do contexto laborioso como, por exemplo, reuniões de amigos ou reuniões de família.

Essa tripartição nos parece muito útil para pensar o fazer do TILSP uma vez que, segundo nossa hipótese e experiência como trabalhador no contexto da interpretação, é na primeira relação, "linguagem como trabalho", que encontramos o cerne de sua atividade. O TILSP está alocado, do ponto de vista da realização da atividade, exatamente no meio de duas línguas; mais que isso, entre diferentes culturas que são expressas por diferentes sujeitos, o discurso é o seu "objeto" de trabalho. "Objeto" este que é tecido, literal e simbolicamente, pelas suas mãos, corpo, olhar, gesto.

No entanto, o enquadramento do trabalho do TILSP na divisão "linguagem como trabalho" não exclui o fato de que, durante o seu fazer, exista um falar que o atravessa, isto é, que haja uma "linguagem no trabalho", pois, conforme aponta a reflexão de Nouroudine (2002), durante as atividades que possuem a linguagem como constituinte do fazer industrioso, é a diferença entre "atividade" e "situação" que permite distinguir o "como" do "no" trabalho.

Certamente todo processo de linguagem requer atividade (NOUROUDINE, 2002), mas estamos tratando aqui de um fazer que se funda completamente nela e nas devidas complexidades que aí se instauram. A atividade de trabalho do TILSP, pensando a "linguagem como trabalho", denuncia aspectos que estão aquém da própria tradicional manifestação da linguagem humana, visto que este trabalhador lida, cotidianamente, com línguas em que a materialidade dessa linguagem se constitui de outros modos, gesto-visualmente (para língua de sinais) e oral-auditivamente (para a língua oral) e colocam esse profissional naquilo que Schwartz (1998; 2004; 2007) denominou de "dramáticas do uso de si".

Esse conceito, que considera todos os percalços e conflitos inerentes à atividade de trabalho, nos oferece possibilidades de observar, analisar e compreender os diferentes atravessamentos que ocorrem durante a atuação do TILSP. Isso porque a dramática ${ }^{9}$ corresponde a uma

\footnotetext{
${ }^{9}$ Ou dramatique, conforme no original francês, proposto por Schwartz (1998).
} 
situação em que o indivíduo tem de fazer escolhas, ou seja, arbitrar entre valores diferentes, e, às vezes, contraditórios. Uma dramatique é, portanto, o lugar de uma verdadeira micro-história, essencialmente inaparente, na qual cada um se vê na obrigação de se escolher, ao escolher orientar sua atividade de tal ou tal modo. Afirmar que a atividade de trabalho não é senão uma dramatique do uso de si significa ir de encontro à ideia de que o trabalho é, para a maioria dos trabalhadores, uma atividade simples de "execução", que não envolve realmente sua pessoa (SCHWARTZ, $1998, \mathrm{~s} / \mathrm{p})$.

O "uso de si" de que fala Schwartz acontece em dois polos diferentes, mas que se fundam na atividade. Para o autor o "uso de si" é "por" e "pelos outros" fazendo com que a atividade de trabalho seja mais complexa do que parece: "todo trabalho é problemático - problemático e frágil - e comporta um drama" (SCHWARTZ, 2007, p.196). Essa bipolaridade do "uso de si" presente na atividade de trabalho precisa ser permanentemente gerida pelos sujeitos que a protagonizam, porque o "uso pelos outros" que cruza, como foi dito, toda a atividade de trabalho relaciona-se diretamente ao "uso de si por si”, pois há sempre um destino a ser vivido e ninguém poderá excluí-lo dessa exigência (SCHWARTZ, 2007, p.196).

Em outras palavras, dramática envolve escolhas, escolhas envolvem responsabilidade/responsabilização e elas, por sua vez, envolvem o assumir posicionamento de diferentes lugares. Traduzir/interpretar significa escolher e responsabilizar-se, porque aquilo que se traduz/interpreta, uma vez que o discurso do locutor, para chegar ao interlocutor, passa pelo intérprete que, ao realizar escolhas, está alocado em determinado ponto, espaço, lugar sóciohistórico.

Em outras análises (NASCIMENTO, 2011;2012; 2013; NASCIMENTO, et. al. 2012) temos mostrado alguns aspectos que revelam esses usos por parte do TILSP e, com eles, as diversas dramáticas inerentes à atividade de interpretação e que podem ser desveladas na dimensão enunciativo-discursiva desse ato, com toda a responsabilidade ética/estética que ele envolve.

Podemos encontrar essas dramáticas reveladas, de maneira mais contundente, por exemplo, na atuação do Intérprete Educacional (IE). Lacerda (2009), em detalhada descrição da atuação do IE de Libras no contexto da educação infantil e do ensino fundamental, revela que, muitas vezes, os professores com quem os Intérpretes atuam não preparam suas atividades pedagógicas considerando a presença de um aluno surdo em sala 
de aula, o que faz com que, então, eles chamem para si a responsabilidade do processo de aprendizagem do aluno surdo que acompanham: "Elas não pedem a colaboração da professora nessas situaçóes, tomando a tarefa como sua, procurando levar os alunos à construção dos conceitos pretendidos, a partir de seus próprios recursos." (LACERDA, 2009, p.76).

A dramática posta em situaçôes de interpretação educacional, por exemplo, denuncia a necessidade de tomada de decisóes que o TILSP deve assumir constantemente durante a sua atividade. As decisões não diferenciariam a atividade de interpretação de outras, já que em todo fazer laborioso existem tomadas de decisões, escolhas e debates (SCHWARTZ, 2004), mas, o que faz com essa atividade se torne demasiadamente dramática em relação a outras, é que o lugar ocupado pelo TILSP, ainda híbrido e indefinido no contexto educacional, por exemplo, o obriga a convocar e a assumir responsabilidades que não lhe são devidas.

\section{O ATO INTERPRETATIVO: perspectiva dialógica}

Dentre os aspectos da linguagem que mais revelam as dramáticas dessa atuação é a questão da autoria (ou coautoria) aspecto constitutivo de todo ato tradutório/interpretativo (SOBRAL, 2008), que representa o sinuoso caminhar desse sujeito entre as linhas que dividem o falar de um lado, o compreender do outro e o falar/compreender do próprio TILSP.

Nesse ponto, o empoderamento do discurso alheio pelo intérprete enquanto enunciador/mediador pode fazer com que ele, enquanto construtor dessa ponte interativa, na verdade, não a construa entre os polos locutor (falante na língua fonte) e interlocutor (receptor na língua alvo), mas de si mesmo (enunciador/mediador) para o interlocutor (receptor da língua alvo na qual o discurso deveria alcançar em toda a dimensão do sentido produzido em língua fonte) (NASCIMENTO, 2011).

Por esse motivo, a atuação do TILSP frente a textos e discursos, tanto em língua de sinais como em línguas orais, estará sempre submetida à compreensão do(s) outro(s) (considerando aqui o TILSP como um "outro" participante dessa interação discursiva em que a sua compreensão também é constitutiva, e fundamental, para a chegada do discurso em língua alvo) e, por isso, ao "uso de si pelo outro", pois "ver e compreender o autor de uma obra significa ver e compreender outra consciência, a consciência do outro e seu mundo, isto é outro sujeito" (BAKHTIN, 2010, p.316). 
Nas palavras de Pereira (2008, p.137):

Ser intérprete é ser, intrinsecamente, um profissional atormentado por ter que estar presente e fingir-se invisível, algo ainda mais impensável para um intérprete de uma língua que é percebida prioritariamente pelo canal visual, como uma língua de sinais; e por não poder ser o 'eu' nem o 'tu' plenamente, por estar sempre em uma posição instável e escorregadia de um simbiótico locutor-interlocutor.

Nesse prisma, consideramos que esse lugar de "tormento" de que fala a autora pode ser desvelado pela dimensão dialógica da linguagem, isto é, na arena de debates que se constitui da arquitetônica sujeitos/discursos/ textos/histórias/esferas/gêneros. Lugar esse que envolve, conforme defendido no tópico anterior, uma "linguagem como trabalho", já que o processo de interpretação da Libras para a língua portuguesa é, por excelência, um ato enunciativo de mediação que envolve não apenas a língua-fonte e língua-alvo em sua prescrição linguística, masécaracterizado pela discursivização entre sujeitos singularmente distintos que desconhecem a(s) língua(s) à qual(às quais) se pretende(m) ter acesso.

Assim como em qualquer enunciação, no ato interpretativo existem sujeitos que falam de determinados lugares sócio-históricos e que, a partir de um projeto discursivo, pretendem alcançar seu interlocutor, desejando que o sentido do seu discurso (aquilo que se pretende dizer) alcance, em sua totalidade, o sujeito que está do outro lado.

Na perspectiva teórica do Círculo e Bakhtin a enunciação é protagonizada, a priori, pela interação entre dois sujeitos, o locutor e o interlocutor; isso porque a palavra comporta duas faces: "[...] ela é determinada tanto pelo fato de que procede de alguém, como pelo fato de que se dirige para alguém" (BAKHTIN/VOLOCHÍNOV, 2009, p.117). Nessa interação, o locutor é aquele que, a princípio, detém a palavra de forma inalienável, é ele o "dono da palavra" (p.117). No entanto, esse seu domínio acontece no momento de materialização dessa palavra, no instante do ato fisiológico de sua externalização, pois a palavra, enquanto produto dessa enunciação é o "território comum do locutor e do interlocutor" (p.117).

Através da palavra, defino-me em relação ao outro, isto é, em última análise, em relação à coletividade. A palavra é uma espécie de ponte lançada entre mim e os outros. Se ela se apoia sobre mim numa extremidade, na outra se apoia sobre o meu interlocutor (BAKHTIN/ VOLOCHÍNOV, 2009, p.117). 
O falante ao enunciar coloca em movimento, no seu enunciado, uma série de respostas que foram construídas na interação com outros falantes em outros momentos históricos, em determinadas esferas ideológicas, sendo ele, nessas interaçōes, ouvinte (empiricamente) ou, mesmo, falante, pois quando interage com outro por meio da comunicação discursiva já assume os dois papéis, isto é, ele é falante-ouvinte/ouvinte-falante.

A interpretação da língua de sinais enquanto ato enunciativo é constituída dessa relação: um sujeito surdo (locutor), falante de língua de sinais, que enuncia de determinada esfera (acadêmica, política, educacional, etc.), e um sujeito ouvinte (interlocutor), que desconhece a língua de sinais e que acessa esse discurso de outro determinado lugar, como auditório social historicamente situado (ouvinte de uma palestra, diretor de uma faculdade, professor do aluno surdo, etc.) e vice-versa.

No entanto, esse acesso só é possível pela intermediação do TILSP, que será chamado aqui de enunciador/mediador. A construção da ponte de que fala Bakhtin/Volochínov (2009) será possível pela presença desse profissional que é responsável pela mediação entre esses sujeitos "discursivamente estranhos". E nessa interação mediada, o construtor dos caminhos de passagem de sentido, o TILSP, lançará mão de recursos que transcendem a palavra, em termos estritamente linguísticos. A relação de transmutação lexical, comum nas práticas de interpretação de profissionais iniciantes, não dará conta da passagem da totalidade de sentido existente no discurso do locutor.

Nessa perspectiva, a prática de tradução/interpretação é abordada como um ato enunciativo-discursivo, pois se constitui de uma prática de linguagem que medeia a interação entre diferentes sujeitos. A interação entre o locutor e o interlocutor, em uma situação de interação que envolve línguas diferentes em que os enunciadores desconhecem a língua um do outro, só é realizada por meio do ato da tradução/interpretação, ou seja, por este ato de enunciação que constrói a ponte discursiva entre locutor e interlocutor.

Encarar a tradução/interpretação como ato enunciativo-discursivo, a partir da perspectiva dialógica de estudos da linguagem, significa enxergar a materialidade produzida nesse ato como um enunciado concreto, concebido como uma unidade real na constante cadeia de comunicação discursiva. Esse enunciado concreto compõe, legitimamente, o discurso e está para além da estrutura da língua, de suas unidades e de seus elementos; esta, na verdade, no uso de seus falantes em determinadas situações e momentos históricos. 
Sobral acentua a questão da tradução/interpretação como enunciado concreto ao afirmar que traduzir significa "[...] mobilizar um texto por meio de outro discurso" (SOBRAL, 2008, p.70) e que o tradutor/intérprete, ao dirigir-se a um público a que um autor não pode se dirigir, cria, necessariamente, novas relações enunciativas e discursivas, isto é, uma nova relação entre o autor e o público.

A especificidade da tradução está no fato de que, em primeiro lugar, o discurso passa a ter, além do locutor e dos interlocutores "originais", um interlocutor que também é locutor (o tradutor) e outro grupo de interlocutores (os leitores da tradução). O discurso a ser traduzido não pode incorporar diretamente esse outro grupo de interlocutores, assim como o discurso gerado pela tradução não pode incorporar os leitores do "original". (SOBRAL, 2008, p.70).

A tradução/interpretação, enquanto ato enunciativo-discursivo é realizado em situações concretas de interação entre sujeitos organizados socialmente e ultrapassa a dimensão linguística, os aspectos lexicais, morfológicos, sintáticos, textuais, pois “[...] essas relações entre enunciações plenas não se prestam à gramaticalização, uma vez que, reiteramos, não são possíveis entre as unidades da língua, e isso tanto no sistema da língua quanto no interior do enunciado" (BAKHTIN, 2010, p.276).

Assim sendo, observar o fazer do intérprete de língua de sinais em situações de trabalho implica mais que realizar uma análise das escolhas linguísticas, enunciativas e discursivas materializadas na sua sinalização, quando o ato interpretativo corresponde do português, enquanto língua fonte, para a Libras, enquanto língua alvo ou, ao contrário, da Libras para o português oral. Observar a atuação desse trabalhador envolve compreender a história que ele carrega, os saberes que se enfrentam durante o seu fazer e os dramas que estão inerentes à gestão desses embates. Por essa razão, defendemos aqui uma análise que não se limita à materialidade da linguagem, mas que abarca a totalidade da situação laboriosa manifesta nela. Defendemos uma análise ergo-dialógica.

\section{A INTERPRETAÇÃO COMO ATIVIDADE DE TRABALHO: dimensão ergo-dialógica}

Concebemos, conforme sinalizado anteriormente, a atividade do TILSP a partir da exploração de Noroudine (2002) em "linguagem como 
trabalho", visto que os discursos são, por excelência, os “objetos" que ele mobiliza no seu fazer. No entanto, para compreender aquilo que objetivamos nesse ato, os dramas e os embates de normas e saberes, utilizaremos a "linguagem sobre o trabalho" que é produzida tanto em situações de interação do trabalhador com outros trabalhadores ou, em nosso caso, em situações de formação em que eles são convidados a narrar experiências sobre o seu fazer.

O narrar sobre o fazer pode ser um elemento importante para a compreensão de alguns aspectos da atividade, mas sabemos que, de certo modo, "o saber que acompanha o gesto na atividade não é imediatamente visível [...]" (NOROUDINE, 2002, p.26). No entanto, esse narrar, quando promovido em coletivo de trabalhadores que realizam a mesma atividade em diferentes lugares, pode ser elemento importante para se identificar os embates e dramas que são comuns a todos sem perder, obviamente, a singularidade dos protagonistas.

Todavia, conforme salienta cuidadosamente Nouroudine (2002), quando a "linguagem sobre trabalho" é adotada como princípio de compreensão da atividade, necessário é conhecer os sujeitos que protagonizam o fazer e falam sobre ele. Nesse ponto o autor chama atenção para uma questão importante, quando "a linguagem sobre o trabalho" é aspecto de investigação, relacionando-a a outras divisões:

É sem dúvida, pertinente o questionamento acerca de "quem fala"? "de onde ele/ela fala?, "quando ele/ela fala?" para que se compreenda onde se situa o campo de validade e de pertinência da 'linguagem sobre o trabalho' [...]. E se, no interior dos coletivos, fala-se do trabalho para transmitir, avaliar, justificar, corrigir [...], então a "linguagem sobre o trabalho" se encontra imbricada com a "linguagem no trabalho" e com a "linguagem como trabalho" (NOUROUDINE, 2002, p.26).

É pertinente questionar "quem fala?", "de onde fala?" e "quando fala?" e, nesse sentido, obedecendo a essa orientação, apresentaremos o relato do trabalhador durante a formação e, na sequência, descreveremos quem é, o que faz e a situação de produção.

\section{A LINGUAGEM "SOBRE O TRABALHO” MOSTRANDO-A "COMO TRABALHO"}

Estava interpretando uma aula de Diagramação no curso de Design Gráfico [para uma aluna surda] e o professor estava 
falando dos diversos modelos e plataformas que os softwares usados nos trabalhos, como photoshop, ilustrator rodavam nos computadores. Ele citou o sistema Windows e depois o da Apple. Aí durante a interpretação eu usei o sinal "NOTEBOOK + MAÇÃ" (Fazendo um classificador, direcionando o sinal de MAÇÃ junto ao NOTEBOOK), pois "achei" que pelo contexto a aluna iria saber que estava me referindo à marca Apple. Ela, então decidiu fazer uma pergunta para o professor e para minha decepção ela disse que também gostava de comer outras frutas enquanto estava no computador, como laranja, mamão, abacaxi... Enfim, minha vontade era sair da sala e ir para casa naquele momento. Ao perceber que a pergunta da aluna não fazia parte do contexto da aula, escolhi não fazer a real interpretação, pois me sentiria muito constrangido ao dizer aquilo e, de certa forma, também pensei em privá-la de tal constrangimento. E a primeira coisa que me veio à mente foi mudar a resposta. Mesmo sabendo da questão ética de fidelidade, optei por não fazê-la.

\subsection{Quem fala? De onde fala? Quando fala?}

O relato acima foi escrito por um profissional TILSP, com idade aproximada de 26 anos e que possui significativa experiência de atuação na esfera educacional, mais especificamente no nível superior. Seu tempo de experiência como TILSP na esfera educacional soma-se em oito anos. Com graduação em outra especialidade que não a da interpretação, ele iniciou seu aprendizado em Libras na esfera religiosa, como a grande maioria desses profissionais, e passou a atuar profissionalmente a convite de colegas que já possuíam experiências como TILSP nesses contextos.

Sua carreira como TILSP começou, fora do contexto religioso, sem grandes prescriçôes de como deveria agir. Oriundo do cristianismo de matriz protestante o autor dessa narrativa começou a trabalhar como intérprete antes mesmo de ter um curso de graduação. Além da aprendizagem inicial da Libras, ele participou de alguns (poucos) cursos e oficinas que ofereceram um aprofundamento de seus conhecimentos linguísticos, bem como uma metarreflexão sobre sua prática cotidiana. Além de trabalhar como TILSP, o sujeito autor da narrativa também é professor dessa língua em cursos livres e em uma instituição de ensino superior. 
O lugar de que fala esse sujeito é o de um profissional que possui anos de experiência de interpretação, mas que, a seu ver, não são suficientes e não o instrumentalizam para que ele possa lidar com as questôes que atravessam cotidianamente seu fazer. Fato que o levou a procurar um curso de formação, em nível de pós-graduação lato sensu, para aperfeiçoar sua prática.

Além das questôes que correspondem à sua atuação, a coerção do contexto brasileiro também o mobilizou a procurar uma formação, uma vez que o exame de certificação promovido pelo Ministério da Educação, PROLIBRAS,${ }^{10}$ segundo o tempo determinado pelo Decreto que o institui, tende a terminar brevemente, obrigando os profissionais atuantes a estarem preparados com cursos de formação e, após o término do prazo, com diploma em mãos para que possam estar "autorizados" a atuar como TILSP.

Os anos de experiência como TILSP do autor dessa narrativa pareceram não serem suficientes, em um primeiro momento, para solucionar o conflito surgido durante sua atuação em sala de aula, e muitas são as hipóteses que poderíamos levantar para encontrar a razão de sua paralisação frente a essa problemática.

A primeira, talvez, seja a de que a falta de uma graduação na área tenha intensificado a dramática da situação, visto que essas questôes poderiam ser antecipadas durante seu processo de formação. Quem sabe a falta de conhecimento de mundo relacionado ao léxico produzido em Libras, naquele contexto específico, por parte da aluna surda, que estava como sua interlocutora direta nesse ato de interpretação, seja um agravante e suscite a problemática macro do processo educacional das pessoas surdas no Brasil ${ }^{11}$

${ }^{10}$ O PROLIBRAS é o exame de proficiência promovido pelo Ministério da Educação para certificação de tradutores/intérpretes e instrutores para o uso, ensino e tradução e interpretação da Libras. Esse exame foi instituído com o Decreto 5626/05 que determina o prazo de dez anos para o seu acontecimento. Segundo o Decreto, após esse período os profissionais precisam apresentar formação em Letras/Libras ou cursos de extensão ou cursos de formação profissional.

${ }^{11}$ A educação de surdos no Brasil é, ainda, um ponto nevrálgico, e tem sido pauta de intensas discussões nas esferas política e acadêmico-científica, com participação de pesquisadores surdos e ouvintes, além da liderança, também surda, dos movimentos de educação bilíngue no Brasil. A constituição de uma educação bilíngue - que é a pauta de reivindicação da comunidade surda - tem se constituído vagarosamente em nosso país, mas foi após a publicação do Decreto 5626/05 que essa modalidade educacional ganhou materialidade, definição e, com isso, embasamento legislativo para garantir à comunidade surda acesso pleno ao direito constitucional à educação. Até meados da 
e, com isso, se justifiquem as dificuldades de compreensão do que havia sido interpretado. Poderíamos, ainda, questionar a habilidade interpretativa do TILSP ou seu conhecimento linguístico para mobilizar esses mesmos discursos produzidos nas línguas envolvidas durante a interpretação.

No entanto, mesmo com tantos possíveis caminhos para justificar ou compreender a atitude descrita de não interpretar o que foi enunciado pela aluna surda durante a interação, o que parece estar latente é que, a prima vista, não houve outro caminho encontrado pelo TILSP para solucionar o problema: ele não possuía, à pronta mão, uma resolução que pudesse abarcar a falta de compreensão do que foi interpretado e, também, evitar o constrangimento vivido ao ver que a contra resposta da aluna surda destoava, por completo, daquilo que estava sendo discutido naquele contexto.

Diante da situação paralisante e da ausência de soluções que resolvessem o problema, o TILSP precisou escolher o que fazer e, então, no vazio que pairou diante de si, ele optou por não interpretar o que foi enunciado pela aluna:

"Ao perceber que a pergunta da aluna não fazia parte do contexto da aula, escolhi não fazer a real interpretação, pois me sentiria muito constrangido ao dizer aquilo e, de certa forma, também pensei em privá-la de tal constrangimento."

No código de ética mencionado pelo TILSP e que foi publicado por Quadros (2007), a questão da fidelidade aparece no capítulo 1 como um dos princípios fundamentais da atuação do intérprete. No artigo $3^{\circ}$ desse capítulo lê-se:

O intérprete deve interpretar fielmente e com o melhor da sua habilidade, sempre transmitindo o pensamento, a intenção e o espírito do palestrante. Ele deve lembrar dos limites de sua função e não ir além de sua responsabilidade.

década de 1980, a educação de surdos no Brasil era pautada pelas práticas oralistas, isto é, a escola de surdos tinha o papel de oferecer aos alunos a possibilidade de apreensão da linguagem oral e, com isso, a aproximação à normalidade ouvinte. Com essa proposta as questôes curriculares ficavam suspensas e os conteúdos eram focados no aprendizado da fala (MOURA, 2000). Nossa hipótese em relação à problemática macro da educação de surdos fundamenta-se nessa questão histórica, visto que alguns dos surdos que vivenciaram o processo educacional nessa época, até meados dos anos 1990, passaram por um processo oralista que desconsiderou as questôes pertinentes aos componentes educacionais curriculares. 
Dentre os pontos mencionados pelo TILSP, o código de ética aparece como uma norma que orienta, de certa forma, o seu fazer. No entanto, consciente do que apregoa o Código, sua escolha foi a de não interpretar o enunciado da aluna, o que evidencia a intensidade do desconforto vivenciado. Nesse ponto observamos, então, a materialização da dramática envolvida no ato de trabalho. A situação, que parece não ser algo comum, em um primeiro momento, em um contexto universitário, colocou o TILSP em uma trama em que, em rápidos segundos, foi necessário avaliar a situação para a tomada de uma atitude.

No seu trabalho como intérprete, havia uma superqualificação dessa interlocutora; ou seja, para ele, o fato de a aluna surda estar em um contexto universitário o fez pressupor que ela carregava os conhecimentos prévios para estar ali e que uma contrarresposta como essa não aconteceria. Desse modo, a contrarresposta fora do contexto discursivo interpretado o deslocou do lugar de profissional intérprete que estava marcado, certamente, no horizonte social imediato pelo posicionamento em sala de aula, à frente da sala, bem como com as relações entre os interlocutores envolvidos na interação (professor e alunos ouvintes) e crachá identificador pendurado no pescoço.

No entanto, o lugar empírico ocupado por ele para a realização da sua função, nesse momento, não foi um ponto que contribuiu para a resolução do seu drama, pois, como estava à frente da sala, tanto os alunos quanto o professor aguardavam pela resposta da aluna que, com a atitude de fazer uma pergunta, chamou a atenção de todos. O lugar empírico, nesse sentido, atenuou a dramática, visto que os olhares, e com eles julgamentos e avaliaçōes, aguardavam pela interpretação do enunciado realizado em Libras.

O TILSP viu seu corpo paralisar-se diante daquilo que variou do comum, do cotidiano, do "convencional" e da norma. Pelo viés ergológico, a variação daquilo que é heterodeterminado previamente pelas normas antecedentes é constitutiva do fazer industrioso e, por isso, constitui a atividade de trabalho como transgressora dos lugares. "Ela mergulha suas raízes, ou seu trabalho, no mais obscuro do corpo, o nosso corpo. E por outro lado, ela tem a ver com o que há de mais cultural, histórico, moral (no sentido da filosofia prática, ou da ética).”(SCHWARTZ, 2007, p.202).

Diante do inesperado, daquilo que ele não poderia prever e pela falta de uma formação prévia na área, que poderia ter sido antecipado ou, pelo menos, discutido as possibilidades de uma incompreensão dos enunciados interpretados em contextos como esse, o trabalhador se encontrou em uma 
situação cujo "uso de si por si" o obrigou a realizar escolhas. Foi necessário que ele atribuísse a si próprio leis para dar conta do que faltava no momento (SCHWARTZ, 2007).

Porém, mesmo sem um "instrumental", um prescrito que o mobilizasse a realizar escolhas que respondessem à atitude esperada pela aluna - fazer uma pergunta para o professor - e do professor - compreender a interpretação da pergunta feita pela aluna - havia, sim, algo que pairava seu fazer e que, segundo os saberes constituidos que ele adquiriu nos poucos espaços de formação que vivenciou, o desestabilizava: as questões éticas envolvidas na escolha que pairava sua mente.

Nesse aspecto entra em cena o debate de valores durante o "uso de si por si" presente em toda atividade de trabalho:

Esses valores podem ser: valores da ordem do político, da ética ou das relaçōes interpessoais - pode ser a angústia de fazer mal feito, que te paralisa, por exemplo. Justamente, a angústia de fazer mal feito é bem conhecida em uma situação de trabalho! Nós conhecemos essa angústia, o que está em jogo nas situações de trabalho nos deixa paralisado... E por trás de tudo o que está em jogo há valores agindo! E quanto às emoções, é preciso submetê-las a esses valores porque eles ultrapassam as emoçôes, eles explicam sua intensidade, as hierarquizam... (SCHWARTZ, 2007, p.205).

No ato em análise, a norma antecedente que regia esse debate interno era o Código de Ética dos TILSP, que é constantemente citado em diversos espaços de formação, mas é pouco explorado e pouco se sabe do que, realmente, ele apresenta. Essa norma, que arbitra sobre questôes não negociáveis da atividade de trabalho do TILSP, pouco diz sobre as situaçôes que estão ligadas às inter-relaçôes estabelecidas durante o ato de interpretação, mas menciona a importância da fidelidade como aspecto constitutivo do fazer laborioso deste profissional.

Quadros (2007), na publicação O tradutor intérprete de língua brasileira de sinais e lingua portuguesa promovida pela Secretária de Educação Especial do MEC, apresenta o código de ética, anteriormente convocado, que faz parte do regimento interno do Departamento Nacional de Intérpretes da FENEIS (Federação Nacional de Educação e Integração dos Surdos). ${ }^{12} \mathrm{O}$

\footnotetext{
${ }^{12}$ A FENEIS, durante muito tempo, foi a entidade que propiciou a organização dos Intérpretes de Libras. Com a organização política da classe e a criação da FEBRAPILS
} 
código apresentado pela autora é uma tradução do código de ética americano, traduzido pelo Intérprete brasileiro Ricardo Sander, expoente político na formação e na organização política de TILSPs, e foi aprovado no II Encontro Nacional de Intérpretes organizado pela FENEIS em 1992. ${ }^{13}$

Embora o código traduza o contexto americano de trabalho de intérpretes de língua de sinais, ele contribuiu com a organização e formalização das práticas dos intérpretes brasileiros. Essa norma antecedente é algo que, geralmente, todo TILSP, especialmente no contexto paulista, sabe que existe, mas poucos sabem, realmente, do que se trata e o que está nele.

Foi esse código que o TILSP, autor da narrativa, invocou em sua memória quando precisou arbitrar uma escolha. No entanto, sabemos que "as normas não antecipam tudo. Então, trabalhar é arriscar, fazer 'uso de si'" (SCHWARTZ, 2011, p.193) e por isso ela foi pouco útil para a resolução da problemática presente na atividade do trabalhador em questão. A escolha de manter uma decisão em função de preservar sua imagem e a da aluna surda não se baseou nesse documento orientador. Ao contrário, sabendo daquilo que o documento orientava, o trabalhador seguiu na direção oposta à da fidelidade apregoada pelo Código.

A escolha de não realizar a interpretação do enunciado produzido pela aluna demonstra, por outro lado, a relação assimétrica presente em toda comunicação discursiva. Essa assimetria denuncia uma relação tripartite dessa interação: em uma ponta, uma locutora/interlocutora surda no lugar de aluna; na outra ponta, um locutor/interlocutor ouvinte no lugar de professor e, no entremeio que liga essas pontas por meio do ato de mediação, o intérprete como enunciador/mediador.

Nesse plano, vemos uma tensão existente entre essas pontas, visto que o TILSP está, justamente, no meio de uma relação de interação e, da perspectiva dialógica, toda interação, encontro, ato envolve tensão

(Federação Brasileira de Tradutores, Intérpretes e Guias-Intérpretes de Língua de Sinais), entidade representativa das associaçōes de interpretes de todo o país, essa responsabilidade descentralizou-se e as discussōes sobre a profissionalização e formação passaram a ser protagonizadas, também, pelos próprios Intérpretes que, de maneira alguma, excluíram a participação da comunidade surda, mas passaram a lidar com essas questôes de outro ponto de vista: o de trabalhadores que precisam de uma representação formal para lidar com as questóes do seu próprio fazer diante da sociedade.

${ }^{13}$ A FEBRAPILS tem organizado, do ponto de vista político, discussōes sobre esse código de ética: a organização de um novo, que se baseie no contexto brasileiro. 
(SOBRAL, 2008). O intérprete, ao escolher não interpretar a pergunta da aluna, deixa atenuar que, na relação presente entre esses polos, a ponta que era ocupada por ele era a que mais importava, naquele instante, para a tomada de sua decisão.

O possível constrangimento que lhe causaria ao interpretar a resposta tão desconexa do contexto foi o que pesou para a sua escolha e foi o peso dessa escolha que o levou a refletir e convocar a existência de uma norma antecedente. Porém, mesmo sabendo dessas questôes, principalmente da existência de uma norma antecedente que poderia pesar sobre a responsabilidade da escolha realizada, o TILSP manteve sua postura em não interpretar o enunciado.

Encontramos em Bakhtin (2010, p.43) o direcionamento e a responsabilização dos atos humanos que colocam o TILSP no enquadramento do drama que estava presente na sua escolha:

$\mathrm{O}$ ato deve encontrar um único plano unitário para refletir-se em ambas as direções, no seu sentido e em seu existir; deve encontrar a unidade de uma responsabilidade bidirecional, seja em relação ao seu conteúdo (responsabilidade espacial), seja em relação ao seu existir (responsabilidade moral), de modo que a responsabilidade espacial deve ser um momento de uma única e unitária responsabilidade moral.

Todo ato possui uma dupla direção. $\mathrm{O}$ ato de interpretação, não diferente de outros atos, possui esse duplo direcionamento e acentua e mobiliza o antecedente, o presente e o real, durante a atividade. Nesse sentido, [...] levar em conta apenas os resultados da atividade significa tomar a decisão de ocultar essas múltiplas dramáticas da atividade (SCHWARTZ, 2007, p.134). Pensar apenas nos "resultados" do processo de compreensão do surdo sem levar em conta o processo interpretativo significa desconsiderar todos os atravessamentos inerentes à atividade de interpretação e à condição de trabalhador assumida pelo TILSP. Essa condição, ainda em construção, é, aos poucos, desvencilhada das atividades assistencialistas do contexto religioso para a construção e constituição de uma identidade profissional.

O debate de valores presentes no ato de trabalho e, em nosso caso, do trabalho interpretativo acentuam a necessidade de se pensar antecipações para o fazer desses profissionais. $\mathrm{Na}$ abordagem ergológica todo trabalho é passível de renormalização, pois as normas antecedentes não respondem às necessidades reais da atividade de trabalho. Todavia, vimos, com a narrativa analisada, que as renormalizações não arbitram sobre as normas 
antecedentes, aquelas que são estabelecidas pelo saber constituidolacadêmico; as renormalizações são mobilizadas no saber investido, que ganha, pela ausência de um prescrito, status de norma que orienta o fazer.

\section{7. À GUISA DE CONCLUSÃO}

O relato analisado teve por objetivo compreender, por meio de categorias que podem ser utilizadas para observar, descrever e analisar diferentes corpora que envolvem o tradutor/intérprete em situações de trabalho, as dramáticas envolvidas durante sua atuação que se manifesta, dentre outras dimensões, nas escolhas enunciativo-discursivas realizadas durante o ato interpretativo. Elegemos a "linguagem sobre o trabalho" para abordar a atividade do TILSP e compreender as escolhas, os dramas, as (in) soluções, as histórias e as interações presentes durante a atividade de interpretação.

Longe de promover um julgamento para a escolha realizada pelo protagonista da narrativa, nosso interesse foi o de realizar, conforme propóe a abordagem ergológica, um deslocamento para o lugar que ocupa esse trabalhador. No entanto, nosso deslocamento, mesmo sendo um tanto enviesado devido à nossa experiência como TILSP nesses mesmos contextos, envolve o que Schwartz (2007) chama de desconforto intelectual. Essa abordagem convoca o pesquisador a se aproximar da realidade do trabalhador para compreender, de um ponto mais próximo possível, a realidade que se busca compreender.

A situação analisada aponta para a necessidade real instaurada no contexto brasileiro em relação à inclusão social de surdos e, por consequência, à profissionalização e a emergencialidade de uma formação que contemple, de maneira mais abrangente possível, o fazer e os atravessamentos envolvidos na atividade de trabalho do TILSP.

Faz-se necessária a construção de um saber constituído, que possa orientar o debate de valores e o uso de si desses profissionais na atividade de trabalho. No entanto, chamamos a atenção para a importância da constituição de um saber a partir dos saberes investidos por esse trabalhador durante a atividade de interpretação. E o contexto que está posto atualmente é esse: intérpretes, trabalhadores, que estão deslocando-se de seu ambiente prático, devido à coerção legislativa, para uma formação acadêmica. Os formadores, as instituições e os pesquisadores precisam, portanto, lidar com os saberes que são trazidos por esses sujeitos e, com eles, os dramas, as 
renormalizações, as histórias, as escolhas, as vozes e os debates, considerandoos na constituição de uma formação que nasce do investimento prático na realidade da atividade, mas que caminha para a sua constituição enquanto norma e prescrição.

\section{REFERÊNCIAS}

ATHAYDE, M.; BRITO, J. Apresentação à edição brasileira: um livro ferramenta diálogo e seu uso na perspectiva Ergológica tecida entre nós. In: SCHWARTZ, Y.; DURRIVE, L. Trabalho \& Ergologia. Niterói: EDUFF, 2007.

BAKHTIN, M. M. (VOLOCHINOV, V. N.). Marxismo e filosofia da linguagem: problemas fundamentais do método sociológico na ciência da linguagem. Tradução: Michel Lahud e Yara Frateschi Vieira. 11 ed. São Paulo: Hucitec, 2009 [1929].

BAKHTIN, M. M. (VOLOCHINOV, V. N.). Para uma filosofia do ato responsável. Trad.: Valdemir Miotello e Carlos Alberto Faraco. São Carlos: Pedro \& João Editores, 2010.

BRASIL. Lei 10.436, de 24 de abril de 2002. Dispóe sobre a Lingua Brasileira de Sinais (LIBRAS) e dá outras providências. Disponível em: <http://www.planalto.gov. br/ccivil_03/LEIS/2002/L10436.htm> Acesso em: 20 de janeiro de 2010.

BRASIL. Decreto 5.626, de 22 de dezembro de 2005. Regulamenta a Lei no 10.436, de 24 de abril de 2002, que dispóe sobre a Lingua Brasileira de Sinais - Libras, e o art. 18 da Lei no 10.098, de 19 de dezembro de 2000. Disponível em: <http://www. planalto.gov.br/ccivil_03/_ato2004-2006/2005/decreto/d5626.htm> Acesso em: 20 de janeiro de 2010.

LACERDA, C. B. F. Intérprete de Libras em atuação na educação infantil e no ensino fundamental. Porto Alegre: Editora Mediação, 2009.

FAITA, D. Análise das práticas linguageiras e situações de trabalho: uma renovação metodológica imposta pelo objeto. In: SOUZA-E-SILVA, M. C.; FAITA, D. (Org.). Linguagem e trabalho: construção de objetos de análise no Brasil e na França. São Paulo: Cortez, 2002.

FRANÇA, M. No princípio dialógico da linguagem, o reencontro do Homo loquens com o ser humano industrioso. In: FIGUEIREDO, M.; ATHAYDE, M; BRITO, J. et al. (Org.). Labirintos do trabalho: interrogaçōes e olhares sobre o trabalho vivo. Rio de Janeiro: DP\&A, 2004.

MOITA LOPES, L. P. Uma Linguística Aplicada mestiça e ideológica: interrogando o campo como linguista aplicado. In: MOITA LOPES, L. P. Por uma linguística aplicada (in) disciplinar. São Paulo: Parábola Editorial, 2006.

MOURA, M. C. O Surdo: caminhos para uma nova identidade. Rio de Janeiro: Revinter, 2000. 
NASCIMENTO, M. V. B. Interpretação da língua brasileira de sinais a partir do gênero jornalístico televisivo: elementos verbo-visuais na produção de sentidos. (Dissertação) Programa de Linguística Aplicada e Estudos da Linguagem. São Paulo: LAEL/PUC-SP, 2011.

NASCIMENTO, M. V. B.; BEZERRA, T. C.; ALBRES, N. A.; SANTIAGO, V. A. Formação de intérpretes educacionais de Libras: entre concepçóes e propostas de curso de extensão universitária. Anais do V Congresso Brasileiro de Educação Especial. São Carlos: UFSCar, 2012. Disponível em: http://www.porsinal.pt/index. php?ps=artigos\&idt $=$ artc\&cat $=16 \&$ idart $=341$

NASCIMENTO, M. V. B. Contribuições bakhtinianas para o estudo da interpretação da língua de sinais. TradTerm, São Paulo, v.21, p.213-236, 2013. Disponível em: http://myrtus.uspnet.usp.br/tradterm/site/images/revistas/ v21n1/13_vinicius21f.pdf

NASCIMENTO, M. V. B. Interpretação da Libras para o português na modalidade oral: considerações dialógicas. Tradução \& Comunicação. Revista Brasileira de Tradutores. v.24, p.79-94, 2012. Disponível em: http://sare.anhanguera.com/index. php/rtcom/article/view/3733/1368

NOROUDINE, A. A linguagem: dispositivo revelador da complexidade do trabalho. In: SOUZA-E-SILVA, M. C.; FAITA, D. (Org.). Linguagem e trabalho: construção de objetos de análise no Brasil e na França. São Paulo: Cortez, 2002.

PEREIRA, M. C. P. Interpretação interlíngue: as especificidades da interpretação de língua de sinais. Cadernos de Tradução, Florianópolis, UFSC/PGET: 2008. Disponível em: https://periodicos.ufsc.br/index.php/traducao/article/view/21757968.2008v1n21p135

PEREIRA, M. C. P. Produções acadêmicas sobre interpretação de língua de sinais: dissertaçōes e teses como vestígios históricos. Cadernos de Tradução, v.2, n.26. Florianópolis, UFSC/PGET, 2010. Disponível em: https://periodicos.ufsc.br/ index.php/traducao/article/view/2175-7968.2010v2n26p99/14225

QUADROS, R. M. Educação de surdos: a aquisição da linguagem. Porto Alegre: Artmed, 1997.

QUADROS, R. M. O Tradutor Intérprete de Lingua Brasileira de Sinais e Lingua Portuguesa. Brasília: MEC/SEESP, 2007.

ROSA, A. S. Entre a visibilidade da tradução da lingua de sinais e a invisibilidade da tarefa do intérprete. Dissertação (Mestrado em Educação). Campinas: UNICAMP, 2005.

RUSSO, A. Intérprete de língua brasileira de sinais: uma posição discursiva em construção. Dissertação (Mestrado em Educação). Porto Alegre: UFRGS, 2009. 
SILVA, C. A. A. Entre a deficiência e a cultura: análise etnográfica de atividades missionárias com surdos. Tese [Doutorado]. São Paulo: USP/FFLCH/ Departamento de Antropologia, 2010.

SCHWARTZ, Yves. Manifesto por ergoengajamento. In: BENSASSOLI, P. F.; SOBOLL, L. A. P. (Org.). Clínicas do Trabalho: novas perspectivas para compreensão do Trabalho na atualidade. São Paulo: Editora Atlas, 2011.

SCHWARTZ, Yves. Trabalho e uso de si. In: SCHWARTZ, Yves; DURRIVE, Louis Trabalho \& Ergologia. Niterói: EDUFF, 2007.

SCHWARTZ, Yves; DURRIVE, Louis. Trabalho \& Ergologia. Niterói: EDUFF, 2007. SCHWARTZ, Yves. Trabalho e Saber. Trabalho \& Educação - vol.12, n.1 - jan/jul. 2003. Disponível em: http://www.portal.fae.ufmg.br/seer/index.php/trabedu/ article/viewFile/1227/989

SCHWARTZ, Yves. Circulações, dramáticas, eficácias da atividade industriosa. Trabalho, Educação e Saúde. 2 - 2004. Disponível em: http://sites.univprovence.fr/ ergolog/Bibliotheque/Schwartz/Circul_dramaticas_Yves_Schwartz.pdf

SCHWARTZ, Yves. Os ingredientes da competência: um exercício necessário para uma questão insolúvel. Educação \& Sociedade, v.19, n.65. Campinas, 1998. Disponível em: http://www.scielo.br/scielo.php?pid=S0101-73301998000400004\&script=sci_ arttext

SOBRAL, A. Dizer o "mesmo" a outros. Ensaios sobre tradução. São Paulo: SBS, 2008. SOBRAL, A. O ato "responsível" ou ato ético, em Bakhtin, e a centralidade do agente. SIGNUM: Estud. Ling., Londrina, n. 11/1, p.219-235, jul. 2008.

SOUZA-E-SILVA, M. C. P. Atividade de linguagem, atividade de trabalho: encontro de múltiplos saberes. Revista Intercâmbio, volume XVIII: 1-21, São Paulo: LAEL/PUC-SP, 2008.

SOUZA-E-SILVA, M. C. P. A dimensão linguageira em situaçōes de trabalho. In: SOUZA-E-SILVA, M. C.; FAITA, D. (Org.). Linguagem e trabalho: construção de objetos de análise no Brasil e na França. São Paulo: Cortez, 2002.

SOUZA-E-SILVA, M. C.; FAITA, D. (Org.). Linguagem e trabalho: construção de objetos de análise no Brasil e na França. São Paulo: Cortez, 2002.

SKLIAR, C. Os Estudos Surdos em Educação: problematizando a normalidade. In: SKLIAR, C. (Org.). Surdez: um olhar sobre as diferenças. Porto Alegre: Medicação, 2005.

STROBEL, K. O olhar do outro sobre a cultura surda. Florianópolis: Editora da UFSC, 2008.

Data de submissão: 06/03/2014. Data de aprovação: 03/07/2014. 
